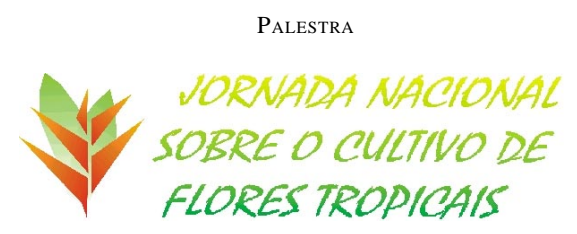

\title{
Cuidados na colheita e na pós-colheita das flores tropicais
}

\author{
JULIANA DOMINGUES LIMA ${ }^{(1)}$ e MARCELO VIEIRA FERRAZ ${ }^{(2)}$
}

\section{INTRODUÇÃO}

As flores tropicais apresentam características positivas para comercialização, tais como: beleza e durabilidade. Muitas espécies ornamentais tropicais são nativas do Brasil, que têm condições de clima e solo favoráveis à produção em larga escala de flor de corte de excelente qualidade.

Do ponto de vista econômico, o agronegócio de flores de corte no Brasil constitui uma atividade promissora com grande perspectiva de crescimento no mercado interno e principalmente no mercado externo. Entretanto, esse crescimento depende de uma política agressiva de marketing, no sentido de despertar, internamente, o consumo de flores, e, sobretudo, de uma política de melhoria do produto ofertado em termos de qualidade e sanidade, atendendo dessa forma, as exigências, cada vez maiores, do mercado internacional.

Para que todo o processo de formação da qualidade das flores de corte se complete com sucesso, muitos cuidados são necessários, desde a escolha adequada da espécie e variedade, material de propagação de ótima qualidade, estrutura de cultivo adequada, além do conhecimento das técnicas de produção e pós-colheita, e de um sistema eficiente de comercialização (MOTOS, 2000).

O material genético, sua adaptação às condições ambientais e condições de cultivo adequadas são fatores pré-colheita que, em conjunto, definem a qualidade do produto final a ser colhido. A interferência em fatores póscolheita não aumenta a sua qualidade, apenas aumenta sua longevidade. Assim, o abastecimento do mercado de modo contínuo e com qualidade, deve ser uma preocupação constante dos produtores de flores durante todas as fases do processo produtivo.

\section{COLHEITA}

Em relação ao horário, a colheita deve ser efetuada com temperatura mais amena, no início da manhã ou final da tarde, para evitar exposição ao calor excessivo após o corte, o que pode causar desidratação das hastes (LOGES et al, 2005). Porém, muitas vezes devido ao intenso ritmo de colheita na propriedade, a colheita acaba sendo feita em horários mais quentes do dia, quando os tecidos estão menos túrgidos, o que resultará em menor resistência, ao estresse da colheita.
O processo geralmente é manual, o que permite a seleção das flores no ponto de colheita mais adequado. $\mathrm{O}$ corte deve ser feito na base da haste com ferramenta afiada, que pode ser uma tesoura ou lâmina, para evitar o esmagamento dos vasos condutores. É recomendável que se faça a desinfestação da ferramenta utilizada, pelo o menos após o corte de cada canteiro, para prevenir a disseminação de doenças. Para tal, pode ser utilizada uma solução com hipoclorito de sódio a 5\% (OLIVEIRA, 1995).

O ponto de colheita de uma flor equivale a um estádio de abertura, que poderá ser completada com sua colocação somente em água. Varia muito em função da região, época do ano, condições de cultivo (campo ou estufa), variedade e distância do mercado. Portanto, a colheita deve seguir recomendações regionais (LAMAS, 2002), atendendo padrões de qualidade definidos especificamente para cada material vegetal.

Padrões de qualidade levam em conta aspectos externos da qualidade como a estrutura floral (forma, comprimento); o número de flores e botões; a ausência de resíduos químicos, de pragas e doenças e de defeitos aparentes; e como internos, a longevidade em condições de interior; a resistência contra condições de estresse durante transporte e comercialização; a suscetibilidade ao resfriamento e etileno; ausência de defeitos escondidos e estabilidade da cor em condições de interior (NOORDEGRAAF, 1994).

Segundo CASTRO (1988), o estádio de botão deve ser o preferido, quando possível, pois nessa condição o manuseio é facilitado e as flores são menos susceptíveis a condições ambientais desfavoráveis como alta temperatura e baixa umidade relativa e a ação do etileno. Esse ponto de colheita não é comum, mas pode ser utilizado para algumas espécies. Outra possibilidade é a colheita no estádio "de vez", devido a menor possibilidade de dano para as flores, desde que seja possível boa abertura da flor após a colheita. A colheita da haste com a flor aberta é, sem dúvida, a que apresenta maior risco de perda.

Muitas vezes, em função da distância do mercado, da exigência do consumidor, da demanda ou da liberação do espaço para produção, a colheita necessita ser antecipada em relação ao melhor momento. No entanto, a colheita precoce pode não permitir o bom desenvolvimento da haste floral, assim como a colheita tardia pode comprometer a qualidade, diminuindo a vida pós-colheita, gerando insatisfação no consumidor.

\footnotetext{
(1) Engenheira Agrônoma, Doutora em Biologia Vegetal. Campus Experimental de Registro - UNESP - e-mail:_judlima@ registro.unesp.br

(2) Engenheiro Agrônomo, Doutor em Agronomia. Campus Experimental de Registro - UNESP - e-mail: ferraz@ registro.unesp.br
} 
Para que haja abastecimento contínuo do mercado, pequenos produtores necessitam produzir muitas variedades num mesmo espaço, o que proporciona uma seqüência de colheita conforme o ciclo, podendo ser alterada, em condições de climas mais frios. Essa situação pode acarretar problema de falta de flores num determinado momento ou ocupação por mais tempo do espaço nas estufas.

Para antúrio, o ponto de colheita mais adequado é quando a espata está totalmente expandida e a espádice madura (flor aberta) em metade do seu comprimento (NOWAK e RUDNICKI, 1990).

Para alpínia (Alpinia spp.) o melhor ponto de colheita é quando o terço superior das brácteas se encontra totalmente expandido, devendo ser colhida a haste floral inteira com pelo menos um centímetro de diâmetro.

A colheita de estrelícia (Strelitzia spp.) deve ser realizada quando os floretes ainda estiverem fechados (NOWAK e RUDNICKI, 1990) e a inflorescência deve ser arrancada da planta e não cortada.

Para maior durabilidade das inflorescências de helicônia (Heliconia spp.) a colheita deve ser feita quando as mesmas estiverem bem hidratadas, para isso recomendase a irrigação das plantas da touceira um dia antes do corte, sendo as hastes florais colhidas quando há de duas a cinco brácteas abertas. $\mathrm{O}$ corte deve ser em diagonal na base da planta, deixando pelo menos de 10 a $15 \mathrm{~cm}$ do pseudocaule junto à haste. Há na maioria das espécies de helicônias folhas acima das inflorescências, que devem ser eliminadas para dar à haste uma melhor aparência, porém, os pecíolos das duas folhas mais próximas da inflorescência devem ser mantidos cerca de dez centímetros acima desta (LOGES et al. 2005) para proteção durante o transporte.

O sorvetão ou gengibre ornamental (Zingiber spectabile) dever colhido com os tecidos bem-hidratados, com remoção de toda inflorescência, ou seja, a haste inteira que deve ter pelo menos $15 \mathrm{~cm}$ de comprimento. $\mathrm{O}$ ponto de colheita varia desde a fase de botão à inflorescência totalmente expandida.

Para bastão-do-imperador (Etlingera elatior) o ponto de colheita varia de botão até brácteas totalmente expandidas, sendo $60 \mathrm{~cm}$ o tamanho mínimo das hastes florais para comercialização.

É comum no procedimento de colheita, esperar o acúmulo de hastes para proceder o transporte até o barracão onde serão realizadas as operações subseqüentes. $\mathrm{O}$ ideal seria que as hastes colhidas fossem levadas imediatamente para locais sombreados e as bases imersas em água, para que haja restabelecimento imediato do fluxo de água nos vasos do xilema, de modo a evitar a perda da turgescência dos tecidos. $\mathrm{O}$ contato direto com a radiação solar promove transpiração excessiva o que é prejudicial, podendo ocorrer um desequilíbrio entre a quantidade de água perdida e a absorvida pela haste, e como conseqüência o surgimento de anormalidade devido à perda de turgescência que compromete a qualidade.
Muitas vezes, dependendo da espécie ou variedade, é recomendável utilizar uma solução com conservante para imersão da base da haste imediatamente após a colheita.

Normalmente a operação de colheita é feita uma ou duas vezes por semana de acordo com o tamanho da área de cultivo e a logística de venda.

O transporte das hastes florais do campo para o local de beneficiamento e armazenamento deve ser feito de maneira rápida e cuidadosa. Para evitar danos, o meio de transporte e os recipientes devem se adequados.

É desejável que o produtor faça um controle de produção, identificando a data de colheita, a quantidade colhida, o talhão, a variedade, e outras informações importantes. Com a competitividade cada vez maior, a coleta de dados de produção tem-se tornado imprescindível. Não se pode mais produzir sem identificar quais as respostas obtidas com os investimentos que são feitos na propriedade. Tudo se resume no aumento de produtividade, de qualidade e redução de custo. $O$ controle da produção servirá de base para tomada de decisão, como, por exemplo, de investir ou descartar uma variedade com base na suas características desejáveis ou produtividade (OLIVEIRA, 1995), ou ainda para o rastreamento do produto.

\section{PÓS-COLHEITA}

Um dos principais problemas que a floricultura brasileira precisa superar é o manejo pós-colheita inadequado. Ainda faltam conhecimentos e tecnologias de colheita e pós-colheita que visem à redução de perdas, que no Brasil chegam a atingir $40 \%$ da produção (DIASTAGLIACOZZO e CASTRO, 2002).

Flores cortadas devem ser encaradas como produto altamente perecível. Portanto, as operações de manuseio, seleção, classificação, embalagem e outras necessárias, devem ser feitas com cautela. Os mecanismos fisiológicos que mantém os tecidos colhidos vivos após o corte são fotossíntese, transpiração e respiração. Para garantir a qualidade e longevidade o ideal é que no produto colhido haja uma redução da respiração e da transpiração e manutenção da fotossíntese.

As flores, assim como os frutos podem ter sua maturação influenciada por etileno e apresentarem comportamento fisiológico climatérico, e, portanto os cuidados no seu manuseio e conservação devem ser ainda maiores.

A duração da flor é específica de cada espécie, sendo cuidadosamente adaptada às exigências ecológicas (ROGERS, 2006). Com a polinização o papel da flor se encerra, disparando processos bioquímicos que resultam na morte celular programada, sendo que, muitas vezes, a senescência das pétalas das flores é mediada pelo etileno (WOLTERING e Van DOORN, 1988). No entanto, em flores tropicais as características estéticas, muitas vezes, são devidas às brácteas e não propriamente às flores, estando as mesmas muitas vezes relacionadas com a polinização. Dessa maneira, supõe-se que também estejam submetidas 
aos mesmos processos bioquímicos e fisiológicos aos quais as flores estão submetidas.

Em diversas espécies ornamentais foi comprovado que o etileno exerce importante papel na aceleração da senescência, resultando na deterioração e abscisão dos tecidos florais, e conseqüente redução da vida pós-colheita. Assim, qualquer fator que estimule a produção de etileno como, por exemplo, dano mecânico ou incidência de patógenos, pode resultar na aceleração da maturação, e como conseqüência da senescência, reduzindo a longevidade da haste floral.

A resposta do tecido vegetal ao etileno é acompanhada pela indução autocatalítica do próprio hormônio, ou seja, a exposição do tecido ao etileno estimula a sua biossíntese, devido ao aumento das enzimas ACCsintase e ACCoxidase. Segundo ALTVORST e BOVY (1995), um dos possíveis mecanismos que contribuem para a indução da biossíntese do etileno é a mudança na receptividade do tecido ou na sensibilidade ao etileno.

Segundo NOWAK e RUDNICKI (1990), as flores de corte variam quanto ao grau de sensibilidade ao etileno, de acordo com a espécie estudada, sendo as liliáceas classificadas como muito sensíveis à sua ação. A idade das flores também é importante, já que se observa a existência de relação direta entre idade da planta e a sensibilidade ao etileno, e quanto mais velho o tecido, menores serão as concentrações de etileno necessárias para desencadear o processo de senescência (PORAT et al., 1995), ou seja, maior sua sensibilidade. Entre as flores tropicais, inflorescências de Anthurium foram consideradas relativamente insensíveis (NOWAK e RUDNICKI, 1990), enquanto Strelitzia spp. e Heliconia spp. sensíveis à ação do etileno (CRILEY e PAULL, 1993). Para outras flores tropicais, como Etlingera elatior e Zingiber spectabilis não foram encontradas informações na literatura sobre a sensibilidade ao etileno.

Para frutos, muitas vezes, recomenda-se um período de repouso após a colheita no galpão de seleção, classificação e embalagem para perda de calor e somente após esse período o seu manuseio. Essa medida também dever ser adotada para hastes florais com estresse acentuado na colheita.

As hastes com flores devem ser cuidadosamente manuseadas, evitando-se danos mecânicos, pois o manuseio incorreto pode estragar, amassar e causar manchas escuras nas flores (DIASTAGLIACOZZO e CASTRO, 2002), além de estimular a produção de etileno.

A seleção e a classificação são operações normalmente realizadas em conjunto de modo manual. $\mathrm{Na}$ seleção é importante a exclusão ou a separação de hastes florais com defeitos, doenças ou pragas, ponto de abertura de flores irregular, ganchos ou botões estragados. A classificação deve seguir os padrões de qualidade estabelecidos para espécie ou variedade. É necessário, na maioria das vezes, fazer a desfolha ou o corte de nivelamento da base da haste, que pode ser feito com serra elétrica, guilhotina ou tesoura, devendo sempre evitar o esmagamento ou o dilaceramento dos vasos condutores da base da haste. Nessas três últimas operações, são freqüentes os danos mecânicos devido ao manuseio e choque contra a superfície de mesas ou bancadas.

A lavagem em água fria visa principalmente a limpeza e o resfriamento das hastes. Todavia, para algumas espécies a lavagem não é recomendada, como, por exemplo, Heliconia rostrata e Heliconia orthotricha, que apresentam escurecimento ou manchas nas brácteas quando umedecidas; Heliconia chartacea Sexy Pink e Sexy Scarlet e Heliconia collinsiana, pois apresentam cerosidade nas brácteas, e podem ficar manchadas após a lavagem; Heliconia episcopalis têm brácteas justapostas que favorecem o acúmulo de água e, conseqüentemente, a deterioração dos tecidos das inflorescências (LOGES et al., 2005).

Na lavagem a qualidade da água é fundamental. Adicionalmente, pode ser necessário o uso de detergente neutro na lavagem, a limpeza manual das inflorescências e caule, imersão da haste em solução contendo inseticidas ou fungicidas, remoção do excesso de água, e imersão da base da haste ou da haste inteira em água ou solução com conservante (solução de tratamento). Alguns autores recomendam também o uso de hipoclorito de sódio a $0,05 \%$ na água de lavagem para desinfestação superficial dos tecidos das hastes.

Para eliminação das pragas presentes em flores cortadas podem ser aplicados inseticidas ou feitas fumigação química, porém muitas vezes a eficiência dos produtos utilizados é baixa e podem ocorrer danos nas flores. Uma das alternativas promissoras ao tratamento químico é a radiação com raios gama ou feixe de elétrons, que reduz a presença de pragas, o que é de extrema importância para colocação desses produtos no mercado externo. Inflorescências de Alpinia purpurata e Strelitzia reginae foram consideradas de baixa sensibilidade à irradiação de feixe de elétrons de $250 \mathrm{~Gy}$, Heliconia stricta considerada de sensibilidade média, enquanto inflorescências de helicônia 'Keanae Red' (Heliconia psittacorum x spathocircinata), Zingiber spectabilis, Costus barbatus e Costus woodsonii sensíveis à mesma intensidade de radiação (SANGWANANGKUL et al., 2008). Contudo, na intensidade $300 \mathrm{~Gy}$, para espécies tropicais, apenas Alpinia pupurata mostrou-se tolerante ao tratamento com radiação gama ou fluxo de elétrons, enquanto Zingiber spectabile, Strelitza reginae, Heliconia psittacorum e Heliconia rostrata mostraramse intolerantes, sendo o escurecimento o dano mais evidente a esse tratamento (KIKUCH, 2003).

Inúmeros trabalhos de pesquisa têm demonstrado o efeito benéfico da adição de produtos químicos conservantes nas soluções de manutenção das flores de corte, dentre esses açúcares e germicidas, como os ésteres de 8-hidroxiquinolina (ROGERS, 1973) e nitrato de prata (ROGERS, 1973; KETSA et al., 1995), que podem duplicar ou triplicar a longevidade das flores. O fornecimento de açúcares, principalmente sacarose, repõe 
carboidratos consumidos pela respiração (NOWAK et al., 1991) e proporciona redução na transpiração das flores e folhas, uma vez que atua no fechamento dos estômatos e na regulação osmótica dos tecidos.

A imersão das flores de corte ou folhas ornamentais em conservantes, condicionamento ou "pulsing", pode ser definida como o tratamento utilizado nas primeiras 24 horas após a colheita, em que estas são saturadas com soluções contendo substâncias químicas, como açúcares, ácidos orgânicos e inibidores da ação ou da síntese de etileno.

O uso de sacarose na solução de condicionamento na concentração de 2 a $20 \%$ ou mais, é muito comum (DIAS-TAGLIACOZZO e CASTRO, 2002). Sacarose prolongou a longevidade de flores de ave-doparaíso, Strelitzia reginae, (Van DOORN e REID, 1992), porém o efeito da solução de sacarose, tanto na forma de condicionamento como na forma de solução em vaso, pode variar consideravelmente entre as espécies. Em várias espécies, além de a sacarose ser eficiente no prolongamento da vida pós-colheita, promove a abertura de botões florais imaturos, permitindo a colheita antecipada e maior vida pós-colheita da flor cortada.

A principal causa de deterioração em flores de corte é o bloqueio dos vasos do xilema por microrganismos, que acumulam na solução do vaso ou nos vasos condutores. Outras causas menos importantes de oclusão vascular são a embolia por ar e a resposta fisiológica da planta ao corte do caule (ICHIMURA et al., 1999). Quando o vaso é bloqueado, o processo de transpiração continua e não ocorre ganho líquido de água pelo tecido da flor ou do caule. Assim, a higiene tem que ser considerada como preocupação importante para flores cortadas (OLIVEIRA, 1995). Flores cortadas não devem entrar em contato com o solo depois de colhidas, devido à possibilidade de partículas do solo entupirem os vasos condutores de água. Microrganismos também podem causar o mesmo problema.

Ácidos orgânicos também podem ser utilizados na solução de condicionamento, com o objetivo de reduzir o pH das soluções, evitando a presença de microrganismos, que podem causar entupimento dos vasos condutores do xilema, assim o pH ácido aumenta a durabilidade das flores. Em Etlingera elatior, a imersão das hastes florais por 24 horas em solução contendo 5\% de sacarose ou $300 \mathrm{mg} \mathrm{L}$ ${ }^{1}$ de ácido cítrico não afetou a longevidade (LIMA et al., 2007).

Germicidas podem ser aplicados para inibir o crescimento de microrganismos nos vasos condutores da haste. Dessa forma, estimula-se a absorção de água, pela redução do bloqueio vascular, contribuindo para a manutenção da turgidez das flores (NOWAK et al., 1991). O composto 8-hidroxiquinolina (8-HQ) é conhecido como um potente bactericida e fungicida, sendo os seus ésteres, citrato 8-hidroxiquinolina (8-HQC) e sulfato de 8hidroxiquinolina (8-HQS) podendo ser utilizados na solução conservante.

A resposta dos tecidos florais ao etileno se dá, provavelmente, pela sua ligação a um receptor específico, responsável por enviar o sinal para sua ativação. Um dos métodos utilizados com sucesso na inibição da produção ou ação do etileno é o tratamento das flores cortadas com o íon prata $\left(\mathrm{Ag}^{+}\right)$, uma vez que este atua como inibidor competitivo da ligação entre o etileno e o seu receptor (ALTVORST e BOVY, 1995). Para flores de corte, tem-se dado preferência à utilização do complexo iônico tiossulfato de prata (STS), por sua boa mobilidade na planta e por apresentar menores problemas quanto à fitotoxidez (CAMPANHA, 1997), além de possuir efeitos germicidas (FLORACK et al., 1996), mas também pode ser utilizado nitrato de prata $\left(\mathrm{AgNO}_{3}\right)$, que possui os mesmos efeitos (Van DOORN et al., 1991). A utilização de nitrato de prata prolongou a longevidade de antúrios (PAULL, 1987) e de Heliconia angusta (OLIVEIRA, 1996).

Para Strelitzia reginae, BAYOGAN et al. (2008) recomendam o seguinte protocolo para que a vida póscolheita seja aumentada de 6 a 8 dias para 14 a 18 dias. Colheita das inflorescências com floretes fechados e remoção do excesso de folhas. Em seguida, as inflorescências devem ser tratadas com uma mistura de $10 \%$ de sacarose, $250 \mathrm{mg} \mathrm{L}^{-1}$ de citrato de 8hydroxyquinoline (8-HQC) e $10 \mathrm{mg} \mathrm{L}^{-1}$ de nitrato de prata $\left(\mathrm{AgNO}_{3}\right)$ por 24 horas. Posteriormente, as hastes florais devem ser embaladas com a base inserida em espuma molhada com água.

Apesar de Anthurium ser considerada relativamente insensível ao etileno, existe recomendação na literatura do uso de $1000 \mathrm{mg} \mathrm{L}^{-1}$ de nitrato de prata na solução de imersão.

O tratamento de Alpinia purpurata com 1metilciclopropeno (1-MCP), um inibidor da ação do etileno, possibilitou menor perda de água, retardando o murchamento, o esgotamento de reservas orgânicas e a senescência das flores (MATTIUZ et al., 2005).

Reguladores de crescimento também exercem efeito benéfico à vida pós-colheita de flores de corte. A citocinina, benziladenida (BA), aplicada na forma de imersão ou spray (BA, $100 \mathrm{mg} \mathrm{L}^{-1}$ ) aumentou a longevidade de inflorescências de Anthurium andreanum, Heliconia psittacorum cv. 'Andromeda', Heliconia chartacea cv. 'Sexy Pink' e de inflorescências vermelha e pink de Alpinia purpurata. Entretanto, benziladenida não teve efeito na vida pós-colheita de Strelitzia reginae, Zingiber spectabile (PAULL e CHANTRACHIT, 2001). Em Heliconia latispatha a aspersão de $300 \mathrm{mg} \mathrm{L}^{-1}$ de benziladenina aumentou 1,85 vez a longevidade em relação às inflorescências não tratadas (MORAES et al., 2003). Hastes de Zingiber spectabile tratadas com solução conservante à base de giberelina e nitrato de prata apresentaram melhor aspecto visual na pós-colheita quando comparadas às hastes não tratadas (SANTOS, 2007).

Com relação a fotossíntese, deve-se manter as hastes em locais claros para que a fotossíntese continue ocorrendo e produzindo substrato para respiração de manutenção.

Adicionalmente ao uso de solução com conservante, deve ser utilizada refrigeração para redução 
da temperatura e a umidade relativa mantida em níveis mais altos (80 a 95\%) proporcionando um controle mais eficiente da perda de água por transpiração, redução da respiração, aumentando a longevidade da haste floral.

Em geral, as flores tropicais por serem originadas de regiões mais quentes apresentam sensibilidade ao frio como Anthurium, Strelitzia, Alpinia e Heliconia (NOWAK e RUDNICKI, 1990), portanto, a temperatura de armazenamento não deve ser muito baixa. Para Strelitzia reginae recomenda-se a temperatura de 7 a $10^{\circ} \mathrm{C}$ e 90 a $95 \%$ de umidade relativa, sendo que a temperatura de armazenamento de $8^{\circ} \mathrm{C}$ permite uma durabilidade de quatro semanas (NOWAK e RUDNICKI, 1990). Para antúrio, a temperatura ideal de armazenamento é 15 a $18^{\circ} \mathrm{C}$ e a umidade relativa de 90 e $95 \%$ (NOWAK e RUDNICKI, 1990). Abaixo de $10^{\circ}$ a $12^{\circ} \mathrm{C}$, ocorrem danos, e as espatas ficam azuladas ou murchas (LAMAS, 2002). Todavia, flores de antúrio 'IAC Eidibel' quando armazenadas a $13^{\circ} \mathrm{C}$ apresentaram maior vida pós-colheita, após a quebra do frio, em termos de qualidade e longevidade, em relação àquelas armazenadas a $18^{\circ} \mathrm{C}$ (LAMAS, 2002). Para Heliconia recomenda-se que o manuseio das inflorescências seja feito em temperatura de 17 e $19^{\circ} \mathrm{C}$ e o armazenamento acima de $14^{\circ} \mathrm{C}$, devido à sensibilidade dessa espécie ao frio (LAMAS, 2002).

\section{CONSIDERAÇÕESFINAIS}

A produção de flor de corte tropical atualmente é um negócio promissor que tem grande perspectiva de crescimento no mercado interno e externo. Contudo, falta ainda uma política de melhoria do produto ofertado em termos de qualidade e sanidade, segundo as exigências do mercado. Visando a aumentar a qualidade do produto final, fatores pré-colheita adequados são fundamentais, pois a interferência em fatores pós-colheita não aumenta a qualidade do produto final, apenas aumenta sua longevidade. $\mathrm{O}$ ponto de colheita deve ser estabelecido em função da espécie ou variedade. Na pós-colheita, as operações de transporte, limpeza, classificação e embalagem devem sem realizadas evitando-se danos. Como alternativa para promover a hidratação e manutenção da vida pós-colheita, podem-se utilizar soluções com conservantes contendo açúcares, ácidos orgânicos, reguladores de crescimento ou outros produtos e, adicionalmente, refrigeração, mantendo-se a umidade relativa em nível elevado.

\section{REFERÊNCIAS}

ALTVORST,A.C.V.; BOVY,A.G. The role of ethylene in the senescence of carnation flower, a review. Plant Growth Regulation, Dordrecht, v.16, n.1, p.43-53, 1995.

BAYOGAN, E.R.V.; JAROENKIT, T.; PAULL, R.E. Postharvest life of Bird-of-Paradise inflorescences. Postharvest Biology and Technology, Amsterdam, v.48, n.2, p. 259-263, 2008.

CASTRO, C.E.F. Diagnóstico técnico-científico da floricultura do Brasil. Piracicaba: ESALQ, 1988. 63p.
CRILEY, R.A.; PAULL, R.E. Review: postharvest handling of bold tropical cut flowers Anthurium, Alpinia purpurata, Heliconia, and Strelitzia. Acta Horticulturae, The Hague, v.337, p.201-212, 1993.

DIAS-TAGLIACOZZO, G.M; CASTRO, C.E.F. Fisiologia da pós-colheita de espécies ornamentais. In: WACHOWICZ, C.M.; CARVALHO, R.I.N. (Org.). Fisiologia Vegetal: produção e pós-colheita. Curitiba: Champagnat, 2002. p.359-382. (Coleção Agrárias).

CAMPANHA, M.M. Manejo pós-colheita de inflorescências de ave-do-paraíso (Strelitzia reginae, Ait.). 1997. 60p. Dissertação (Mestrado em Fitotecnia) Universidade Federal de Viçosa, Viçosa, 1997.

FLORACK, D.E.A. et. al. Toxicity of peptides to bacteria present in the vase water of cut roses. Postharvest Biology and Technology, Amsterdam, v.8, n.4, p.285-291, 1996.

ICHIMURA, K.; KOJIMA, K.; GOTO, R. Effects of temperature, 8-hydroxyquinoline sulphate and sucrose on the vase life of cut rose flowers. Postharvest Biology and Technology, Amsterdam, v.15, n.3, p.33-40, 1999.

KIKUCHI, O.K. Gamma and electron-beam irradiation of cut flowers. Radiation Physics and Chemistry, Oxford, v.66, n.1, p.77-79, 2003.

LAMAS, A.M. Floricultura tropical: Técnicas de cultivo. Recife: SEBRAE-PE. 2002. 87p. (Série Empreendedor).

LIMA, J.D.; NOMURA, E.S.; MORAES, W. da S.; SOUZA, N.A.D. Condicionamento em pós-colheita de pós-colheita de Etlingera elatior (Jack) R. M. Smith. Revista Brasileira de Horticultura Ornamental, Campinas, v.13, suplemento, p.128-128, 2007.

LOGES, V.; TEIXEIRA, M. do C.F.; CASTRO, A.C.R. de; COSTA, A.S. da. Colheita, pós-colheita e embalagem de flores tropicais em Pernambuco. Revista Brasileira de Horticultura Ornamental, Campinas, v.23, n.3, p.699-702, 2005.

MATTIUZ, C.F.M.; MATTIUZ, B.; RODRIGUES, T. de J.D.; DURIGAN, J.F.; PIVETTA, K.F.L. Efeito de agentes químicos na conservação pós-colheita de inflorescências de Alpinia purpurata (Vieill) K. Schum. Revista Brasileira de Horticultura Ornamental, Campinas, Brasileira de Plantas Ornamentais, v.11, n.1, p.1, p.35-42, 2005.

MORAES, P.J.DE; FINGER, F.L.; BARBOSA, J.G; CECON, P.R.; CESA, L.P. Influence of benzyladenine on longevity of Heliconia latispatha Benth (Musaceae). In: INTERNATIONAL SYMPOSIUM ON NEW FLORICULTURAL CROPS, 5, 2003, Foz do Iguaçu. Abstracts...Campinas : IAC, 2003. v.1.p.66.

MOTOS, J.R. A importância dos materiais de propagação na qualidade das flores e plantas. Informativo Ibraflor, Campinas, n.1,2000.

NOORDEGRAAF, C.V. Production and marketing of high quality plants. Acta Horticulturae, The Hague, v.353, n., p.134-148, 1994.

NOWAK, J.; RUDNICKI, R.M. Postharvest handling and storage of cut flowers, florist greens and potted plant. Portland: Timber Press, 1990. 210p. 
NOWAK, J., GOSZCZYNSKA, D., RUDNICKI, R.M. Storage of cut flowers and ornamental plants: present status and future prospects. Postharvest News and Information, Cambridge, v.2, n.4, p.255-260, 1991.

OLIVEIRA, M.J.G. de. Manual sobre pós-colheita de rosas. Holambra: Veiling Holambra, 1995. 41p.

OLIVEIRA, M.J.G. de. Tecnologia pós-colheita de Heliconia spp. Universidade Estadual de 1996, 108 f. Dissertação (Mestrado) - Faculdade de Engenharia Agrícola, Universidade Estadual de Campinas, Campinas, 1996.

PAULL, R.F. Effect of storage duration and temperature on cut anthurium flowers. HortScience, Alexandria, v.22, n.3, p.459-460, 1987.

PAULL, R.E.; CHANTRACHIT, T. Benzyadenine and the vase life of tropical ornamentals. Postharvest Biology and Technology, Amsterdam, v.21, n.3, p.303-310, 2001.

PORAT, R. et al. 1-Methylcyclopropene inhibits ethylene action in cut phlox flowers. Postharvest Biology and Tecnology, Amsterdam, v.6, n.4, p.313-319, 1995.

ROGERS, M.N. A historical and critical review of postharvest physiology research on cut flowers. HortScience, Alexandria, v.8, p.189-194, 1973.
ROGERS, H.J. Programmed Cell Death in Floral Organs: How and why do flowers die? Annals of Botany, London, v.97, n.3, p.309-315, 2006.

SANGWANANGKUL, P.; SARADHULDHAT, P.; PAULL, R.E. Survey of tropical cut flower and foliage responses to irradiation. Postharvest Biology and Technology, Amsterdam,v.48, n.2, p.264-271, 2008.

SANTOS, M.H.L.C. Fisiologia pós-colheita de sorvetão (Zingiber spectabile Griff.) cultivado no submédio São Francisco. 2007. 94 f. Tese (Doutorado) - Faculdade de Ciências Agronômicas Botucatu, Universidade Estadual Paulista, Botucatu, 2007.

Van DOORN, W.G; GROENEWEGEN, G; van de POL, P.A.; BERKHOLST, C.E.M. Effects of carbohydrate and water status on ower opening of cut Madelon roses. Postharvest Biology and Technology, Amsterdam, v.1, n.1, p.47-57, 1991.

Van DOORN, W. G.; REID, M. S. Role of ethylene in flower senescence of Gypsophila paniculata L. Postharvest Biology and Technology, Amsterdam, v.1, n.3, p.265-272, 1992.

WOLTERING, E.J.; Van DOORN, W.G. Role of ethylene and in senescence of petals: morphological and taxonomical relationships. Journal of Experimental Botany, Oxford, v.39, n.208, p.1605-1616, 1988. 